Adriano Monteiro de Brito, Rosinei Batista Ribeiro, João Eduardo Chagas Sobral, Wellington de Oliveira *

\title{
Engenharia Kansei como Pressuposto Para o Desenvolvimento de Processos de Design e Criação em um Jogo Educativo
}

Adriano Monteiro de Brito é Designer. Mestre em Design, Inovação e Tecnologia no Centro Universitário Teresa D’Ávila- UNIFATEA. Pesquisador do LAPEDLaboratório de Pesquisas em Design e Educação na mesma instituição. $<$ drianomonteiro.design@gmail.com > ORCID: 000-0002-1343-1593
Resumo Este artigo tem como objetivo apresentar e discutir processos de design envolvidos na elaboração do protótipo de um jogo digital para tablets e smartphones com foco na intervenção comportamental em tratamentos de sintomas do autismo. As crianças autistas possuem uma grande dificuldade no entendimento de emoções humanas, e partindo dessa necessidade a ideação do jogo é concebida para fornecê-las esse tipo de conteúdo, um meio lúdico e educativo que as ensinem de forma subjetiva sobre emoções e também as auxiliem a desenvolverem e aprimorarem outras habilidades, como coordenação motora, raciocínio rápido, diferenciações, entre outros. Com base nos dados levantados sobre autismo e desenvolvimento infantil e com o auxílio da metodologia Kansei, o jogo consiste no uso de uma personagem como elemento chave, por meio dela o jogador passa ter contato com o conteúdo de ensino brincando, havendo interações com a personagem e suas emoções, que são respectivamente baseadas nas ações realizadas.

Palavras chave Design, Emoção, Jogo para Autista, Game Mobile, Jogo Educativo. 
Rosinei Batista Ribeiro é Pós-Doutorado em Engenharia de Materiais no Instituto Tecnológico de Aeronáutica (ITA). Doutorado e Mestrado em Engenharia Mecânica pela Universidade Estadual Paulista Júlio de Mesquita Filho (FEG-UNESP). Pró-Reitor de Pesquisa, Pós-Graduação e Extensão e Docente Permanente no Programa de Mestrado Profissional em Design, Tecnologia e Inovação no Centro Universitário Teresa D’Ávila (UNIFATEA). Líder do Grupo de Pesquisa "Projeto de Produto e Tecnologias Sociais", registrado no Diretório de Grupos de Pesquisa do CNPq. Docente Permanente no Programa de Mestrado Profissional em Gestão e Tecnologia em Sistemas Produtivos no Centro Estadual de Educação Tecnológica Paula Souza (CEETEPS).<rosinei1971@gmail.com > ORCID: 0000-0001-8225-7819

João Eduardo Chagas Sobral é Doutor em Design e Sociedade pela PUC-Rio, Mestre em Educação pela Universidade Regional de Blumenau (FURB), graduado em Comunicação Visual pela Universidade Federal de Pernambuco (UFPe). É professor titular da Universidade da Região de Joinville, coordena o Programa de Pós-Graduação em Design e o projeto de pesquisa Design e Processos e do Laboratório Iris. É membro do corpo técnico-científico do Grupo Assessor Especial da Diretoria de Relações Internacionais (DRI-CAPES); consultor Ad hoc da FAPESC, CAPES e do Conselho Estadual de Educação de Santa Catarina. Coordenador do Fórum Nacional de Pós-Graduação em Design. >sobral41@gmail.com> ORCID: 0000-0001-5758-9985

\section{Kansei Engineering asa bases for the Development of Design and Creation Proces- ses in an Educational Game}

Abstract This article aims to present and discuss design processes involved in the development of the prototype of a digital game for tablets and smartphones with a focus on behavioral intervention in the treatment of symptoms of autism. Autistic children have great difficulty in understanding human emotions, and based on this need, the ideation of the game is designed to provide them with this type of content, a playful and educational means that teach them subjectively about emotions and also help them to develop and improve other skills, such as motor coordination, quick thinking, differentiation, among others. Based on the data collected on autism and child development and with the help of the Kansei methodology, the game consists of using a character as a key element, through which the player comes into contact with the teaching content while playing, with interactions with the character and their emotions, which are respectively based on the actions taken.

Keywords Design; Emotion; Autistic Game; Game Mobile; Educational Game.

\section{La Ingeniería Kansei como presuposición para el desarrollo de procesos de diseño y creación en un juego educativo}

Resumen Este artículo tiene como objetivo presentar y discutir los procesos de diseño involucrados en el desarrollo del prototipo de un juego digital para tabletas y teléfonos inteligentes con un enfoque en la intervención conductual en el tratamiento de los síntomas del autismo. Los niños autistas tienen una gran dificultad para comprender las emociones humanas, y en base a esta necesidad, la ideación del juego está diseñada para proporcionarles este tipo de contenidos, un medio lúdico y educativo que les enseñe subjetivamente sobre las emociones y también les ayude a desarrollar y mejorar otras habilidades, como coordinación motora, pensamiento rápido, diferenciación, entre otras. Basado en los datos recopilados sobre autismo y desarrollo infantil y con la ayuda de la metodología Kansei, el juego consiste en utilizar un personaje como elemento clave, a través del cual el jugador entra en contacto con el contenido didáctico mientras juega, con interacciones con el personaje. y sus emociones, que se basan respectivamente en las acciones realizadas.

Palabras clave Diseño; Emoción; Juego autista; Game Mobile; Juego educativo. 


\section{Introdução}

Wellington de Oliveira é Doutor e pós-doutor pela Pontifícia Universidade Católica de São Paulo. Professor permanente do Programa de estudos pós-graduados em Design, Inovação e Tecnologia no Centro Universitário Teresa D'Ávila- UNIFATEA e coordenador do LAPED- Laboratório de Pesquisas em Design e Educação na mesma instituição. <reitoria@fatea.br>

ORCID: 0000-0003-0523-5645
Partir de uma necessidade para atender um todo é um ponto chave do desenvolvimento projetual. Os autistas dispõem de certas especificidades e perturbações no relacionamento social que acaba gerando uma demanda de cuidados diferenciados, desta maneira, aqueles que possuem esse tipo transtorno mental acabam possuindo um distúrbio de relacionamento com o ambiente, que muitas vezes pode ser descrito como, "viver em seu próprio mundo" (Asperger, 1994).

Com essa grande dificuldade em expressar emoções e compreendê-las em outros indivíduos, os obstáculos para os autistas tornam-se cada mais desafiadores. A busca pela inclusão destas pessoas e o estímulo para o desenvolvimento produtivo é alvo de investimento em diversos países. Governos e empresas buscam inserir no mercado produtos e serviços que proporcionem experiências a favor desta necessidade.

Os jogos, especialmente digitais, vem sendo um dos recursos mais utilizados para este campo, propiciando grandes resultados. Esses jogos proporcionam aos seus usuários momentos de satisfação repletos de experiências positivas, e a partir desse princípio eles são explorados para recursos educativos, afinal, para o usuário é mais prazeroso aprender de uma forma dinâmica e divertida como é provido nos jogos.

Este projeto teve sua origem em conjunto ao Laboratório de Pesquisas em Educação, Tecnologia e Design (LAPED) pertencente ao Centro Universitário Teresa D’Ávila (UNIFATEA), partindo de uma concepção multidisciplinar, com visões e experiências de áreas e profissionais diversos, desta maneira, imergindo no problema de pesquisa com perspectivas diversificadas. Contudo, seu prefácio se dá a partir de um projeto de graduação financiado pelo Conselho Nacional de Desenvolvimento Científico e Tecnológico (CNPq), orientado pelo Prof. Dr. Wellington de Oliveira, com foco nos estudos emocionais voltados para o público infantil, que posteriormente evolui para este protótipo adequado às necessidades de um público mais específico.

\section{Desenvolvimento Projetual do Jogo Digital com Base na Engenharia Kansei}

A Engenharia Kansei é explorada por suprir essa necessidade de projeto, sendo ela, uma metodologia voltada para estímulos emocionais, contudo, para uso em conjunto, é aderido as 8 etapas de projeto na criação de jogos digitais concebido por (Novak, 2010) são alinhados para trabalharem em conjunto a metodologia, permitindo assim, a união de ambos artifícios, a relação emocional e o jogo como métodos construtivos.

Em seguida todas as informações até então adquiridas são sintetizadas e organizadas para que se possa executar testes de validação e também atuarem em conjunto no processo de criação descrito por (Novak, 
2010), aderindo a cocriarão de métodos voltados a jogos digitais e estímulos emocionais, para que por fim seja concebido a construção de um modelo (mock-up) digital. Em muitos casos de projetos para games, são elaborados uma pequena sinopse sobre a proposta dos jogos, seja no lançamento ou até mesmo para a venda do projeto ainda não finalizado podendo ter intuito da aquisição de colaboradores e/ou patrocinadores.

A fase de coleta das Palavras Kansei se assemelha muito a uma ferramenta muito utilizada no campo do Design conhecida como Brainstorm ${ }^{1}$, porém, mais direcionada a questões ligadas a razões emocionais, como sentimentos do usuário, gatilhos para despertar interações, mecânicas, etc. Estipulando um período máximo de uma hora com um total de quatro pessoas de áreas distintas; Design, Arquitetura, Pedagogia e Marketing, é anotado o maior número de palavras que possa ter relação ao conteúdo proposto, seja diretamente ou indiretamente sem julgamentos de fazerem sentido ou não para depois serem filtradas.

Com um total de 207 palavras e com o auxílio de um editor de planilhas elas são classificadas em três grupos distintos também classificado por cores; cuidado ao aplicar no desenvolvimento do projeto (vermelho); características desejáveis para o jogo (azul); demais palavras que podem impor determinada inspiração (verde).

Abordagem; angústia; cores; custo; desânimo; distração; estresse; jogador; limitação; pedagogia; pressão; resistência; sons; tédio; tempo.

Ensino; afeto; ajuda; animado; ansiedade; aplicativos; Apple Store; autismo; aventura; brincadeiras; brincar; capacidades; celular; cognição; comunicação; conforto; cotidiano; criança; curiosidade; design; diferente dificuldade; diversão; educação; ergonomia; estímulo; expectativa; experiência; família; felicidade; foco; game; gargalhadas; Google Play; gostos; habilidades; histórias; identidade; independência; individua ; interação social; interativo; interesses; interface; jogo; legal; mascote; motivação; multiplayer; Off-line; On-line; oportunidade; pensamentos; relacionamento; sensorial; sentidos; smartphones; sorriso; tablet; usuário; valor; viajar.

Abstrato; açōes; adaptação; administração; agitação; ambiente; amor; anúncios; aparelho; aplicação; atenção; avatar; cálculo; calma; carência; cenário; compaixão; compatíveis; competitivo; comportamento; comum; concentração; conforto. conquistas; contato; coordenação; cuidados; cultura; dependente; desafio; desempenho; desenho; desenvolvimento; desprezo; diálogo; distinta; entretenimento; escola; especificidades; espontaneidade; estímulo exterior; evolução; exatidão; exclusão; exercício; expansão; expressão; facilidade; família; fazer; ficção; fonoaudióloga; formação; funções; futuro; identificar; imersão; incomum; infância; inocência; inspiração; integrar; intelecto; interpretação; interpretar; itens; joystick; liderança; linguagem; lúdico; mecânica; medo; memória; mercado; mudanças; mundo; música; normalidade; objetos; padrão; passatempo; perseverança; persistência; personalidade; pesquisas; pessoa; planejar pontuação; popular; posicionamento; prática; preocupação; processo; produtividades; projeto; protótipo; psiquiatra; puzzle; rápido; realidade; reconhecimento; recursos; referências; reflexão; repeticăo; requisitos; seriedade; serviço; sinceridade; síndrome; sistema; solidão; sonhos; tamanho; tarefa; tecnologia; transtorno:

traumas; tristeza; vício; vida; virtual; vontade; cuidado.

Com a análise é cabível constatar elementos que são decisivos na concepção de projeto e execução, exercendo como ideias e características atenuantes que devem ser levadas em consideração.

Buscou-se em seguida a análise de informações de jogos disponíveis no mercado e com base nos resultados levantados, distinguiu-se aqueles jogos mais comuns e que trazem para as crianças autistas uma relação educativa. 
ABC Autismo é um jogo de destaque em fase Beta baseado na metodologia TEACCH desenvolvido pela Dokye Mobile, seu objetivo consiste em auxiliar no processo de aprendizagem por meio de atividades de assimilação de tamanho, cor e forma disponíveis em 3 idiomas.

Já o jogo Brainy Mouse, aplicativo vencedor de mais de 17 mil projetos do prêmio Santander em 2013 (Santander, 2014), busca auxiliar no estímulo da linguagem e alfabetização de crianças autistas por meio de um personagem que através da atividade trabalha a leitura da direita para esquerda, formação de palavras usando sílabas, interação com cores, sons e outros "dispositivos cognitivos".

Embora Minecraft não seja um jogo mobile de início nem possua o foco exclusivo no autismo ou no desenvolvimento infantil, o jogo ganhou repercussão não apenas nesse público como em crianças por todo o mundo se tornando um sucesso. 0 jogo eletrônico funciona em mundo aberto que possibilita a construção de diversos elementos, como casas, monumentos, mecanismos, armadilhas entre outros, usando blocos dos quais o mundo é feito, explorando a criatividade de seus jogadores e permitindo que outros jogadores interajam entre si ou não, e hoje conta com um servidor exclusivo para autistas conhecido por "Autcraft" com mais de 8,2 mil participantes (The Might, 2018).

O jogo Pokémon Go é um aplicativo para usuários Android e IOS que conta com a combinação da geolocalização com a realidade aumentada, com a necessidade de seus jogadores saírem de suas casas para procurar monstrinhos por diferentes locais pela cidade, e quando encontrados, os mesmos podem aparecer interagindo com o cenário por meio da câmera do smartphone para serem capturados.

o jogo não parecia traduzir uma forte relação ao público autista, entretanto, por se tratar de um jogo altamente cooperativo, ou seja, necessitar de outros jogadores para realizar determinadas atividades passou a incentivar a interação para com outros jogadores, assim como autistas, sendo comum ver um grupo de cerca de 6 ou mais pessoas reunidas para fazer uma missão de 10 minutos.

Outro similar relevante e marcante no final do século XX não é unicamente um jogo digital, mas um brinquedo que trouxe as crianças um forte apelo emocional, o Tamagotchi também conhecido como "bichinho virtual", consistia no ato de brincar e cuidar de um bichinho no aparelho cujo era levado pelas crianças para todo lugar, era preciso alimenta-lo, realizar atividades, banho e outros cuidados, até mesmo socializar com outros "bichinhos virtuais" dos amigos, que com o tempo foram evoluindo, ganhando novas dinâmicas no jogo, cores, tamanho e modelos. Um simples personagem com poucos pixels ${ }^{2}$ era capaz de proporcionar as crianças diversos momentos marcantes que jamais esqueceriam. $O$ laço afetivo entre usuário e personagem era tão forte que a preocupação por cuidar de seus 
Tamagotchis era enorme, um animal que ganhava parte no cotidiano e não poderia ser deixado de lado, visto que caso isso ocorra ele morreria para nunca mais voltar, para a tristeza e muito choro de seus usuários, e seria preciso resetar o aparelho para um novo personagem nascer.

Já o aplicativo Minha Rotina Especial lançado em 2015 possui uma característica diferente dos similares analisados, a partir dele é possível elaborar rotinas por meio de fotos personalizadas, embora não seja diretamente um jogo, e sim um mecanismo para o auxílio na rotina, é um recurso muito explorado na educação de crianças autistas e com próprio aplicativo ela passa a compreender sua rotina por meio de sua própria imagem. Entretanto, esse aplicativo necessita de um uso prévio dos pais ou de um profissional para elaborar/inserir os quadros de ações e atividades. Dentre esses mesmo parâmetros de não ser um jogo especificamente, o Livox é um aplicativo em sistema Android para pessoas que possuem dificuldades para ser comunicar para tablets e smartphones, com um sistema de tradução de imagens para comandos de voz quando tocados pelo usuário, sendo indicado para pessoas com Autismo, Esclerose Lateral Amiotrófica, Paralisia Cerebral, Sequelas de AVC/AVE, Síndrome de Down, Traqueostomizados, Trauma Crânio-Encefálico, e outras deficiências ou doenças que impeçam comunicação oral.

Com toda análise abordada, ambos são organizados por meio de um quadro comparativo para observar suas relações, diferenças e destaques em cada similar, dispondo de cada requisito contextualizado por uma ordem de prioridade (1) 2, 3):

\begin{tabular}{|c|c|c|c|c|c|c|c|c|}
\hline & & ABC Autismo & $\begin{array}{l}\text { Brainy } \\
\text { Mouse }\end{array}$ & $\begin{array}{l}\text { Mine- } \\
\text { craft }\end{array}$ & $\begin{array}{c}\text { Pokémon } \\
\text { Go }\end{array}$ & $\begin{array}{l}\text { Tama- } \\
\text { gotchi }\end{array}$ & $\begin{array}{l}\text { Minha Roti- } \\
\text { na Especial }\end{array}$ & Divox \\
\hline 3 & Apelo emocional & & & & & $\checkmark$ & & \\
\hline 3 & Apelo temático & & $\checkmark$ & $\checkmark$ & $\checkmark$ & & & \\
\hline 3 & Associações & $\checkmark$ & $\checkmark$ & $\checkmark$ & $\checkmark$ & $\checkmark$ & $\checkmark$ & $\checkmark$ \\
\hline 3 & Bonificações de amigos & & $\checkmark$ & & $\checkmark$ & & & \\
\hline 3 & Coleta de itens & & $\checkmark$ & $\checkmark$ & $\checkmark$ & $\checkmark$ & & \\
\hline 3 & Diferenciação de cor & $\checkmark$ & $\checkmark$ & $\checkmark$ & $\checkmark$ & $\checkmark$ & & $\checkmark$ \\
\hline 3 & Diferenciação de tamanho & $\checkmark$ & $\checkmark$ & $\checkmark$ & $\checkmark$ & $\checkmark$ & & $\checkmark$ \\
\hline 3 & Gratuito & $\checkmark$ & & $\checkmark$ & $\checkmark$ & & & \\
\hline 3 & História & & $\checkmark$ & $\checkmark$ & $\checkmark$ & $\checkmark$ & & \\
\hline
\end{tabular}



de Design e Criação em um Jogo Educativo

\begin{tabular}{|c|c|c|c|c|c|c|c|c|}
\hline 3 & Mascote & & $\checkmark$ & $\checkmark$ & $\checkmark$ & $\checkmark$ & & \\
\hline 3 & Off-line & $\checkmark$ & & $\checkmark$ & & $\checkmark$ & $\checkmark$ & $\checkmark$ \\
\hline 3 & On-line & & $\checkmark$ & $\checkmark$ & $\checkmark$ & & & \\
\hline 3 & Rotina & & & & & $\checkmark$ & $\checkmark$ & \\
\hline 3 & Transposição de figuras & $\checkmark$ & $\checkmark$ & $\checkmark$ & $\checkmark$ & $\checkmark$ & $\checkmark$ & $\checkmark$ \\
\hline 2 & Alfabetização & $\checkmark$ & $\checkmark$ & & & & & \\
\hline 2 & Colecionismo & & & $\checkmark$ & $\checkmark$ & & & \\
\hline 2 & Comunicação & & & & & & & $\checkmark$ \\
\hline 2 & Exploração da criatividade & & & $\checkmark$ & & & & \\
\hline 2 & Foritificação & & & & $\checkmark$ & & & \\
\hline 2 & Jogo Cooperativo & & & & $\checkmark$ & & & \\
\hline 2 & Missões extras & & & & $\checkmark$ & & & \\
\hline 2 & Moeda Virtual & & $\checkmark$ & & $\checkmark$ & & & \\
\hline 2 & Níveis de dificuldade & & $\checkmark$ & $\checkmark$ & & & & \\
\hline 2 & Outros Idiomas & $\checkmark$ & $\checkmark$ & $\checkmark$ & $\checkmark$ & & $\checkmark$ & $\checkmark$ \\
\hline 2 & Personagens & & $\checkmark$ & $\checkmark$ & $\checkmark$ & $\checkmark$ & & \\
\hline 2 & Ranks & & $\checkmark$ & & $\checkmark$ & & & \\
\hline 2 & Shop & & $\checkmark$ & & $\checkmark$ & & & \\
\hline 2 & Socialização & & $\checkmark$ & $\checkmark$ & $\checkmark$ & & & $\checkmark$ \\
\hline 2 & Tempo extenso & & & $\checkmark$ & $\checkmark$ & $\checkmark$ & $\checkmark$ & $\checkmark$ \\
\hline (1) & Customização & & $\checkmark$ & & $\checkmark$ & & & \\
\hline 1 & Escolha de fases & $\checkmark$ & $\checkmark$ & & & & & \\
\hline 1 & Exposição de ideias & & & $\checkmark$ & & & & \\
\hline
\end{tabular}


de Design e Criação em um Jogo Educativo

\begin{tabular}{|c|c|c|c|c|c|c|c|c|}
\hline (1) & Expressão verbal & & & & & & & \\
\hline (1) & Fases & $\checkmark$ & $\checkmark$ & & & & & \\
\hline 1 & Gerar áudios & & & & & & $\checkmark$ & $\checkmark$ \\
\hline 1 & Gerar relatórios & & & & & & $\checkmark$ & \\
\hline 1 & Gravar áudios & & & & & & $\checkmark$ & \\
\hline 1 & Grupo & & & & $\checkmark$ & & & \\
\hline (1) & Idioma indiferente & & & & & $\checkmark$ & & \\
\hline 1 & Interação RL & & & & $\checkmark$ & & $\checkmark$ & $\checkmark$ \\
\hline 1 & Mais de 1 usuário & & & & & & $\checkmark$ & $\checkmark$ \\
\hline 1 & Mods & & & $\checkmark$ & & & & \\
\hline 1 & Mundo aberto & & & $\checkmark$ & $\checkmark$ & & & \\
\hline (1) & Personalização & & & & & & $\checkmark$ & $\checkmark$ \\
\hline (1) & Plataforma autista & & & $\checkmark$ & & & & $\checkmark$ \\
\hline (1) & Pronúncia & & $\checkmark$ & & & & & \\
\hline 3 & Mobile & $\checkmark$ & $\checkmark$ & & $\checkmark$ & & & \\
\hline 1 & Tablets & $\checkmark$ & $\checkmark$ & & $\checkmark$ & & $\checkmark$ & $\checkmark$ \\
\hline (1) & Brinquedo & & & & & $\checkmark$ & & \\
\hline (1) & PC & & & $\checkmark$ & & & & \\
\hline 3 & Preço & $R \$ 0,00$ & $\begin{array}{c}\mathrm{R} \$ \\
15,99\end{array}$ & $R \$ 0,00$ & $R \$ 0,00$ & $\mathrm{R} \$ 12,00$ & $R \$ 40,00$ & $\mathrm{R} \$$ \\
\hline \multicolumn{9}{|c|}{ Característica única } \\
\hline & & vão é o foco. & (2) Dese & ável. & dispensável. & & & \\
\hline
\end{tabular}

Quadro 1. Quadro comparativo

Fonte: Autor, 2019 
O quadro revela que um jogo em específico possui duas características únicas muito fortes e de grande desejo para o jogo, definindo uma inspiração principal. O Tamagotchi possui um forte apelo emocional devido sua grande conexão dos jogadores para com os "bichinhos virtuais" e uma grande necessidade para com a rotina, sendo fatores característicos para os autistas.

Permitir a fortificação de determinado personagem, seja por um nível de poder ou de habilidade é um elemento que prende o jogador, fazendo-o ter o desejo de ver seus esforços alcançados e o motivando a montar uma rotina. Gerar um laço cooperativo entre os jogadores permite uma desenvoltura direta para com eles, seja por bonificações, como enviar itens diariamente, ou até mesmo a necessidade de amigos para a realização de missões.

Iniciando a fase conceitual conforme os passos de (Novak, 2010) o jogo representará o cotidiano de uma personagem, sem um gênero de sexo aparente, buscando assim uma maior identificação tanto como meninos quanto meninas. A personagem passaria a ter uma relação muito similar ao "bichinho virtual" presente no Tamagotchi, sendo uma amiga virtual, e através dela a criança passaria a interagir com base em diversas atividades do cotidiano.

Além de se divertir durante as atividades como ações e mini-games, a personagem ensinaria ao jogador emoções de acordo com determinadas circunstâncias, desta forma, a criança visitaria essa personagem diariamente, realizaria atividades com ela, brincaria e teria uma relação afetiva direta com ela. 0 jogo é dividido em 2 áreas principais, a tela de interação direta com a personagem, e os mini-games nos quais ele realizaria outras atividades sendo bonificados com itens, tais atividades que servirão de auxílio ao explorar elementos corporais e educativos, como assimilação de cores, coordenação motora, raciocínio rápido, etc.

Como perfil de público-alvo é cabível ressaltar que crianças autistas são caracterizadas por sua individualidade, sendo complexo uma definição específica de idade, visto que cada um pode se desenvolver de forma diferente, além da variação com o tempo de identificação do autismo e o tratamento, entretanto é possível estipular uma faixa etária para os 5 anos com a perspectiva de ser um jogo com características simples com uma classificação etária livre, podendo ter uma dificuldade ampliada a partir de níveis cujo as bonificações sejam maiores, mas, não se limitando a ser jogado em níveis menores.

Os diálogos da personagem necessitam ser curtos e simples, podendo ser audíveis ou não, não sendo de suma importância referente a jogabilidade, mas, que auxilie na parte do ensino emocional, como a personagem contando que sentiu saudades por exemplo, que está feliz, triste, entre outros sentimentos, com a possiblidade de serem acompanhados pelos pais e profissionais no ato de jogar.

O jogo necessita de um clima calmo, sem cores muito fortes e sons agitados, mesmo com a opção de anular sons do jogo e trilha sonora conforme todas as referências estudadas. A música clássica é muito aceita por esse público e pode ser muito bem explorada no desenvolvimento. 
O gênero do jogo é concebido a partir de 3 tipos principais, casual, puzzle e simulação. Os jogos casuais podem ser facilmente descritos como fáceis de se jogar e aprender, permitindo ao jogador se integrar com pouco tempo e dedicação para aprender, ideal para crianças e também muito apreciado para o público acima de 40 anos.

Já os puzzles, explorados em mini-games presentes dentre do jogo, são empregados como meio de conquista de itens para a personagem. Jogos desse estilo são focados em resolver quebra-cabeças independente da dificuldade e do gráfico ligado a ele, variando desde os mais complexos a modelos simples, sendo usado para testes e estimular uma variedade de habilidades, como lógica, estratégia, reconhecimento de padrões, etc.

Os jogos de simulação podem ser divididos em diversas subcategorias conforme o segundo estilo de jogo e sua intensão, alguns jogos desse estilo tem por objetivo simular um universo, seja ele real ou fictício, outros podem explorar habilidades de construção e gerenciamento do jogador mais voltados para o lado estratégico, embora neste caso seja mais voltado para a simulação de uma amizade por um mecanismo digital.

As ilustrações integradas ao jogo, como personagem, itens, e cenários são confeccionados a partir de modelos visuais disponibilizados gratuitamente, adaptações e criações por meio de arte gráfica.

A análise de competitividade é disposta com base na própria analise de similares feita a partir da metodologia kansei, elencando jogos que mais se sobressaem em suas características, tomando ciência dos demais comparativos presentes no mercado sendo especificamente para área autista como ABC Autismo, Brainy Mouse, AutismCPM, Minha Rotina Especial, Livox, Story Creator, Tobii e Tippy Talk.

A personagem atua como uma "representação" de um amigo de verdade, figurando e simulando na mente do jogador um ser de fato para qual ele irá interagir (Gombrich, 1999), pensando em cativar os jogadores, sua concepção consiste em gerar a maior identificação possível por parte de determinados atributos com o público-alvo.

Buscando uma aparência uni gênero, é possível levar ao jogador a imagem da personagem possuir o sexo que ele preferir, sendo feito de forma inconsciente, com base nas experiências já vividas pela criança.

A escolha do nome também parte deste princípio, é necessário um nome que possa usado tanto para uma menina como um menino. 0 nome Dani possui uma pronúncia única, e pode ser atribuída a qualquer gênero, visto que usado como diminutivo tanto de Daniela como de Daniel, sendo de uso comum no Brasil.

Dani é uma personagem que gosta de brincar e realizar diversas atividades como jogar basquete, colorir, fazer contas e tocar piano. Sua expressão inicial não é aberta, e nem muito exaltada, porém receptiva, inspirada em características comuns em sua totalidade, e no uso de cores. 
Fig 1. Personagem Dani e suas características.

Fonte: Autor, 2019.
Fig 2. Expressões faciais da personagem Dani. Fonte: Autor, 2019. de Design e Criação em um Jogo Educativo

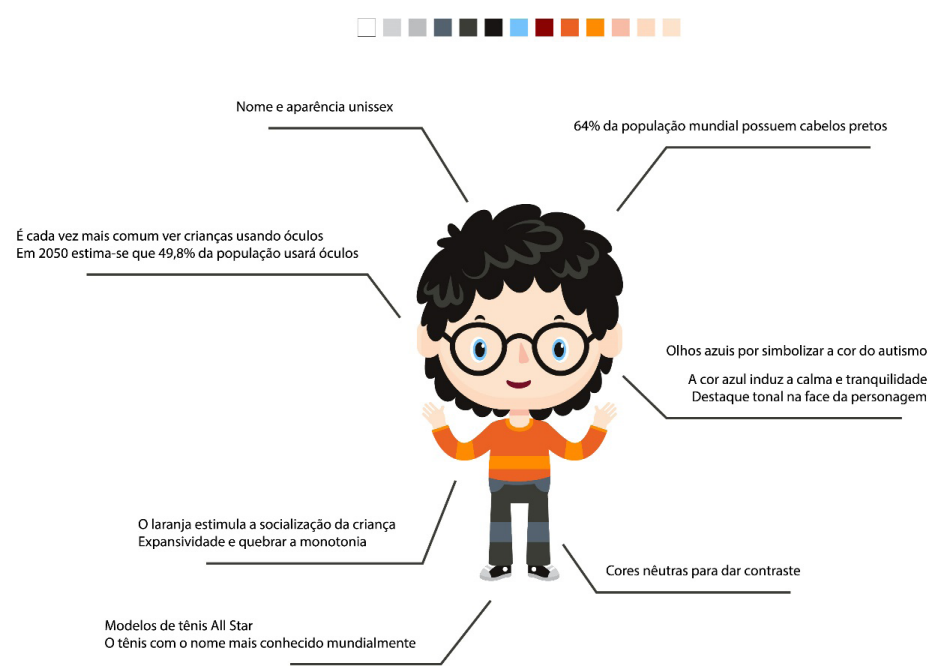

Lucca é uma personagem criada para ser o elo entre o jogo e conteúdo a ser aprendido. Onceito de personagem unissex, tanto por sua aparência, como por seu nome
desta forma permitindo que os usuarios se identifinuem com mais facilidade.

Seus cabelos são pretos inspirado à grande parte da população mundial dispor de cabelos nesta cor, e usa óculos por ser uma tendência a necessidade deste acessório para com o público geral, que além de gerar uma identificação, seja com o jogador ou com um amigo ou parente, acaba o auxiliando a passar por essa fase de aceitação que pode ser um pouco difícil em alguns casos.

Suas cores são inspiradas nos conceitos de (Heller, 2012), e as demais são cores neutras para gerar destaque aos demais elementos, olhos na cor azul para se induzir a calma e tranquilidade, simbolizando o autismo. o laranja de sua blusa está ligado ao estimular a socialização da criança, a expansividade e a quebra da monotonia, desta forma os olhos se destacam na face do personagem, e a blusa em todo entorno.
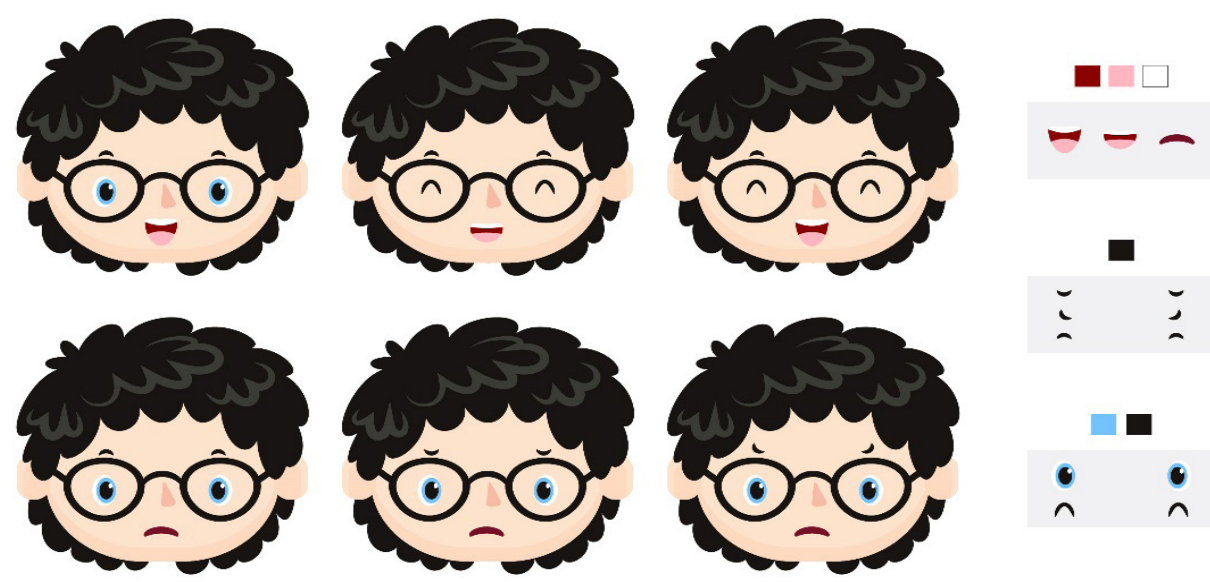
Com a grande dificuldade na percepção de emoções levantadas por (Kanner, 1943), a personagem possui um conjunto com seis expressões faciais diferentes para cada momento e ação no decorrer do jogo, com índices de felicidade, tristeza e raiva, respectivamente conforme a figura anterior possuiu-se: feliz; super feliz; risadas, triste; saudades e irritado. Com uma boa pontuação nos mini-games ou até mesmo ao receber sua comida favorita é possível adotar a face de extrema felicidade pela personagem, ao ato do jogador ficar muito tempo sem visitar seu amigo virtual a personagem ficará com saudades, ao ficar satisfeita ela ficará brava ao receber mais comida, dentre outras ações.

A personagem apresentará uma enorme felicidade ao superar suas habilidades como jogador, ao se alimentar independente de qual seja o alimento, desde que não esteja satisfeita, e ao presentear um amigo. Ao mesmo tempo que poderá se entristecer com emoções negativas, imprimindo uma dinâmica emocional que se articulará diretamente aos movimentos propostos elo jogador, o que, por conseguinte, representa em certa medida a sua estratégia socioemocional para lidar com e nas interações.

No decorrer do jogo também é possível a troca de roupas da personagem permitindo assim um processo de customização por parte do jogador sendo possível trocar 3 partes da vestimenta com pelo menos 2 modelos diferentes.
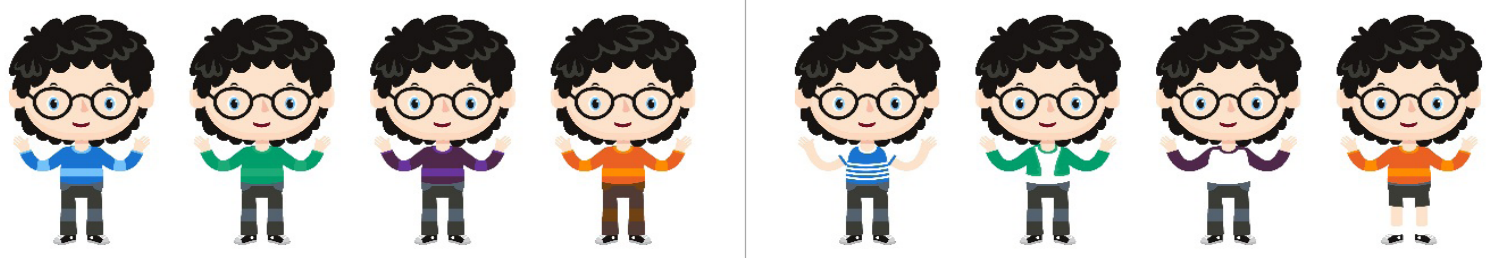

Fig 3. Exemplos de customização da personagem.

Fonte: Autor, 2019.

A Identidade Visual é concebida a partir de um conceito simples, buscando elementos minimalistas e cores solidas, sem grandes efeitos e detalhamentos para não propiciar uma quantidade exarada de informações.

o layout consiste na predominância de tons de amarelo para detalhamento a cor vermelha gera um contraste direto com as cores calmas do jogo sem agredir a visão do usuário.

\section{$13: 47$}

\section{COMPRAR}
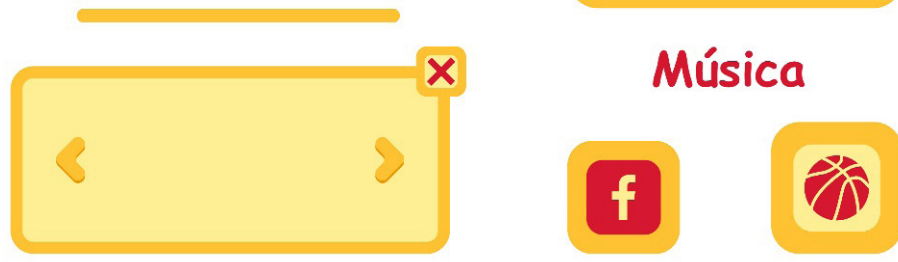
Para dar um efeito de contraste também é usado a cor verde, especialmente para parâmetros em mecanismos, como regulador de som, ligar e desligar, e também em elementos especiais, e grande parte dos ícones utilizados são propriamente da plataforma "Flaticon" ou com alguma variação.

Um fator que propicia uma grande variação em jogos é dado pelo posicionamento da tela, muitos exemplos possuem a característica de serem jogados em telas horizontais, ou seja, é necessário mudar o posicionamento do aparelho no momento de uso do aplicativo.

Essa característica se origina dos jogos tradicionais em televisores e também pela assimilação do formato de joystick, podendo alinhar botões mais facilmente para jogos de ação e aventura. Porém, mesmo perante essa observação as telas no modo vertical vem sendo cada vez mais utilizadas, tanto por jogos como vídeos, com grande aceitação pelo público e uma forma ergonômica de se segurar.

Atualmente os smartphones em sua maioria possuem uma proporção de tela de 16:9, já os tablets de 4:3, e partindo disso é gerado linhas guias para que possa orientar melhor os espaços para a produção. Desta forma o layout é desenvolvido na tela vertical com uma margem de adaptação para diferentes aparelhos conforme demostrado na figura a seguir:

A tela principal segue os parâmetros de jogos tradicionais, com uma barra de experiência acima em conjunto com as moedas virtuais. As ações principais como roupas, loja, enviar presentes, itens e configurações respectivamente são alinhados em baixo, e no segundo grupo com uma zona de respiro há uma janela de horário, e botões que levam aos mini-games.

O modelo de posições desenvolvido ainda permite a adição de ousmartphones para tablets. Fonte: Autor, 2019. tros elementos futuramente, como bônus, missões diárias, anúncios bônus, etc., podendo expandir para novas mecânicas e recursos de jogos. E sua faixa com horário se altera com um texto condizente com a emoção nova da personagem, possuindo a possibilidade de ser expandida para a descrição de falas em futuros testes.

A personagem é alinhada ao centro para ser o foco da atenção do jogador, e ambiente que ela se localiza ao fundo é pensado nos meus requisitos de suas cores, predominando cores azuis, e com dois elementos decorativos para preencher o espaço.

Com o menu de roupas é aberto um novo menu para se possa selecionar qual vestimenta deseja mudar, como camisa, calça e sapatos, e os elementos são alterados por meio das setas em suas laterais, e para finalizar a escolha basta clicar no (X).

A partir do menu de presentes é possível enviar presentes para amigos que contém itens especiais, sendo abertos logo após entrarem no jogo. Os presentes vermelhos são ilimitados e dão itens comuns, já os verdes originam itens mais raros. Estes presentes só podem ser abertos quando recebidos por um amigo, ou seja, esse mecanismo induz uma interação obrigatória. 

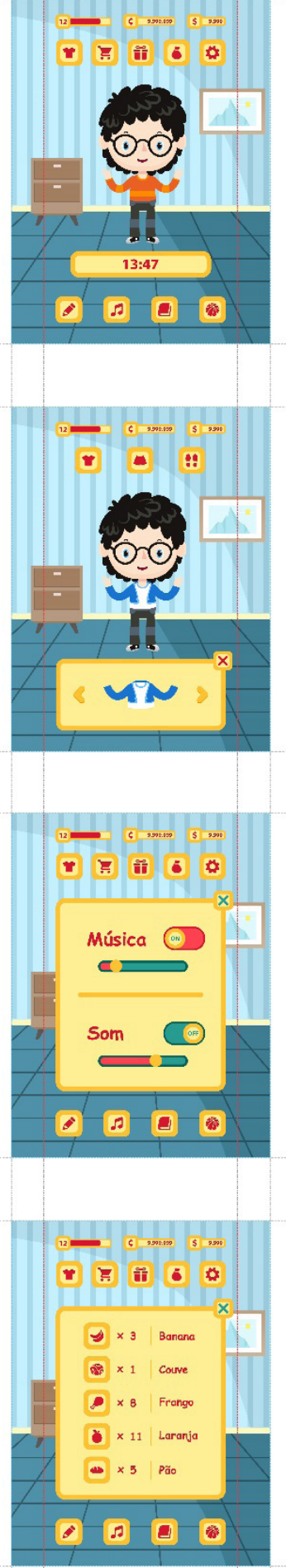

Fig 6. Diferentes telas de interação pertencentes ao momento de jogo. | Fonte: Autor, 2019.
No menu de configurações é possível ajustar o volume de música e som no jogo. Para definir a sonoplastia será realizado um estudo e testes com crianças autistas para que não ocorra a escolha de algo que as irritem e sim sons que mais as agrade. Contudo esses estudos mais aprofundados serão feitos em projetos futuros, visto que o objetivo principal é gerar uma ideação principal de jogo com alguns sistemas e mecanismos que podem ser melhorados e aperfeiçoados em novas etapas.

Os itens também possuem seu menu próprio tido pelos objetos já adquiridos pelo jogador e suas respectivas quantidades, com exceção de roupas por ter seu próprio menu. Diferente do menu de roupas, os itens desse menu são acumulativos podendo ser usados quando desejados, porém, ao fazer isso eles são gastos, perdendo uma quantidade por uso.

Assim como os outros menus eles possuem um "X" para fechar a janela caso o jogador não deseje realizar mais nenhuma ação retornando a tela principal e assim continuando o ciclo de jogo.

Também é simulado uma tela de carregamento, essas telas são fundamentais pois informam ao jogador do processo, não o fazendo pensar que ocorreu algum problema, como travar, ou outro erro por exemplo, dando a ele a informação que está tudo certo e só é necessário aguardar.

Ao entrar no jogo pela primeira vez, o jogador é automaticamente redirecionado a tela de login, nela é possível se conectar com o Facebook, ou com a plataforma da Google para gerar sua conta naturalmente, embora para isso seja necessário conexão com a internet. A princípio pretende-se que o jogo seja offline e apenas durante o momento do primeiro login nessas plataformas e para envios de presentes seja necessária uma conexão com a internet.

Caso o jogador não possua uma conta em uma das plataformas mencionadas, ou não queira usá-las, seja por preferência própria ou por permissões de seus responsáveis, ele pode criar uma conta, levando-o para uma outra tela, onde bastaria adicionar seu nome e sua idade sem a necessidade de uma conexão com a internet.

O nome é um requisito para diferenciá-lo dos demais jogadores, porém podem haver nomes iguais sem problemas, e o requisito de idade unicamente para ter parâmetros de perfis de usuários ativos para futuras atualizações.
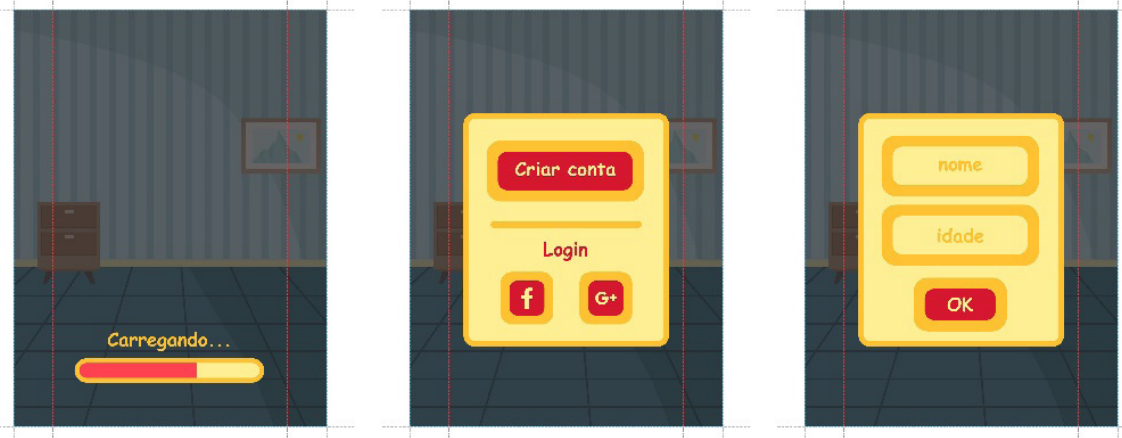

Fig 7. Tela de carregamento, login e criação de conta respectivamente | Fonte: Autor, 2019. 
A partir dos mini-games as crianças desenvolvem e exercitam determinadas habilidades se divertindo, há 3 níveis diferentes em cada atividade que são liberadas ao atingir 3 estrelas no nível atual.

Os mini-games são realizados a partir de um certo período de tempo, desta forma o nível possui um limite de tempo de 60 segundos, o nível 2 de 90 segundos e o 3 de 120 segundos, com o objetivo de realizar o maior número de tarefas nesse espaço de tempo.

A atividade de "Arremesso de Bola" como o próprio nome diz consiste em lançar uma bola de basquete no cesto logo a frente. A partir desta dinâmica a criança consegue exercitar sua coordenação motora e melhorar sua noção espacial por meio da profundidade e direção

$\mathrm{Na}$ atividade de "Estudo Matemático" o objetivo consiste responder corretamente as operações apresentadas na tela, desta forma clicando nos botões e confirmando com o botão "igual" (=). Sendo uma atividade para melhorar sua desenvoltura no raciocínio rápido além treinar conhecimentos matemáticos. No nível mais fácil são apresentados apenas equações de adição e subtração, já no segundo a operação é seguida de uma multiplicação e outra adição e subtração, e no mais difícil a operação é tida inicialmente por uma multiplicação ou divisão, e outras duas operações de adição e/ou subtração sempre com resultados de números inteiros.

A mecânica "Aprendendo Música" por outro lado busca não só desenvolver habilidades de observação como também usa o som como intuito de memorização. Cada uma das 4 teclas centrais do piano emite uma nota musical diferente, e o objetivo do jogo é repetir essa sequência, sendo cada vez maior o número e a velocidade das repetições de cada nível.

A dinâmica "Colorindo" busca especificamente a diferenciação de cores, a princípio é elaborado 5 cores principais, porém também serão realizados estudos futuros em quais os 5 melhores valores tonais pensando em pessoas que possuem algum tipo de dificuldades visuais como o daltonismo por exemplo. Após cada cor alinhada corretamente ela é substituída por uma nova e a partir daí é contabilizado a pontuação.

o livreto tem o objetivo principal de passar toda a essência do projeto de forma resumida e visual atendo-se a cativar leitor relatando a motivação principal para com crianças autistas, assim como os benefícios para esse público como para com outras crianças.

Fig 8. Telas de mini-games

Fonte: Autor, 2019. 

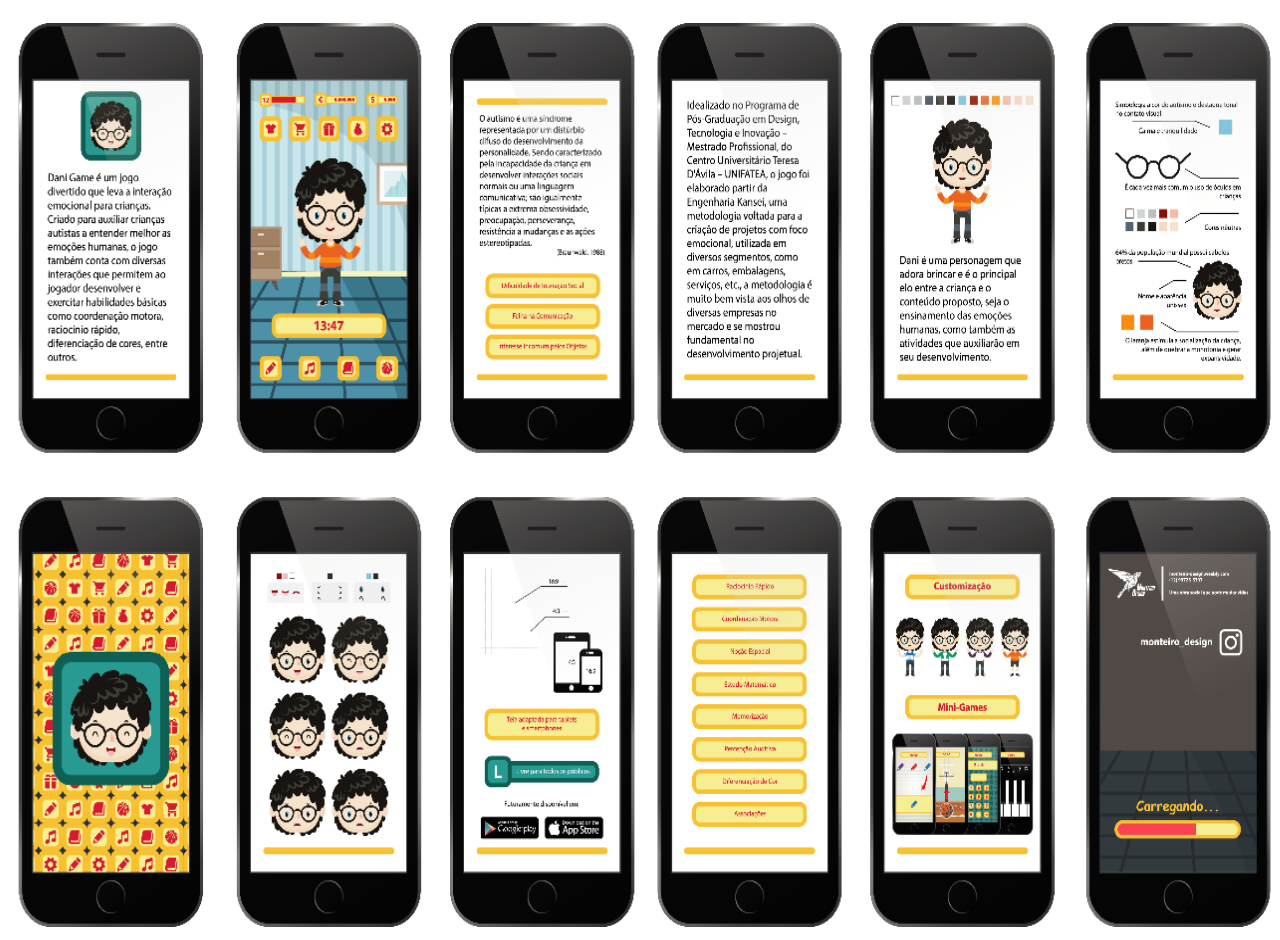

Fig 9. Livreto (concept)

Fonte: Autor, 2019.

\section{Considerações Finais}

Neste projeto concebido a partir de pesquisas desenvolvidas no LAPED- Laboratório de Pesquisas em Design e Educação foi possível levantar elementos para o papel do jogo como recurso afim de auxiliar no desenvolvimento de crianças autistas, especificamente aplicado para passar a elas no contexto das emoções humanas, visto ser uma de suas maiores dificuldades de compreensão.

A partir do grande acesso a smartphones e o grande uso de tablets por crianças a plataforma mobile se mostrou capaz de atingir o público destinado de forma mais efetiva quando comparada as demais. Através dos resultados levantados os jogos nessa plataforma tendem a crescer cada vez mais, além de serem muito explorados para objetivos similares.

Partindo desses princípios foi possível constatar ser necessário planejar como o jogo atuaria em ambos os aparelhos, visto que possuem dimensões de telas diferentes, desta forma, o formato do uso no momento de jogar foi levado em consideração, posicionamento de tela na vertical para facilitar a pega e margens de adaptações para os aparelhos foram fundamentais para garantir o melhor uso do produto. 
Por meio de um protótipo foi possível estipular um modelo de jogo educativo que explora não apenas sua causa principal, as emoções, como também a intervenção de outras mecânicas para ajuda-las a desenvolver e aprimorarem outras habilidades. Com a desenvoltura dos mini-games diversas outras habilidades são exploradas por meio de atividades diferenciadas, para que a criança possa jogar e evoluir ao mesmo tempo, seja pelo raciocínio rápido, pela diferenciação de cores, logica matemática, entre outras.

Com a carência na compreensão emocional a personagem criada se tornou um elo direto entre o jogo e o conteúdo a ser aprendido, que desta maneira permite que o jogador interaja diretamente com ela através de tarefas simples e sem muita complexidade, visando atender também crianças de uma faixa etária mais reduzida. A personagem tem o papel principal de passar para a criança a importância dos sentimentos, visto que com a base nas ações feitas por elas a personagem reagiria de maneiras diferentes, com resultados positivos ela transparecia afeições mais alegres, porém, com ações negativas, como a ausência do jogador em um determinado tempo por exemplo ela passaria a demonstrações afeições tristes como a saudade.

Por se tratar especialmente de uma razão social, desenvolver uma ferramenta que traga benefícios à pessoas com essa necessidade, o jogo não possui um objetivo comercial, porém, há também a possibilidade de ser explorado este recurso, não como pré-requisito, como um preço de venda, ou anúncios obrigatórios por exemplo, mas sim, com sistemas de bonificações de propaganda, que demonstra ser uma mecânica viável cujo jogador pode ter a opção de assistir determinado anúncio e como consequência ganha algo por isso, o mantendo assim no controle das ações no jogo, não permitindo que haja uma frustação por elas.

1 Coleta de palavras e/ou ideias em determinado um tempo estipulado sem restrições de pensamentos.

2 Menor elemento em um dispositivo de exibição (por exemplo, um monitor), ao qual é possível atribuir-se uma cor 


\section{Referências}

ASPERGER, A. Autistic psychopathy in childhood. In U. Frith (Ed.), Autism and Asperger syndrome (p.37-92). Cambridge University Press, 1994.

CHACON, A. A Utilização de Jogos Digitais no Cenário Educacional. Disponível em: <http://www.fabricadejogos.net/posts/artigo-a-utilizacao-de-jogos-digitais-no-cenario-educacional>. Acesso em 12 out. 2019.

FGV. 28 Pesquisa Anual de Administração e Uso de Tecnologia da Informação nas Empresas, 2017. Disponível em: <http://bibliotecadigital.fgv.br/>. Acesso em 31 out. 2019.

FLATICON, Plataform free for search grafic, 2018. Disponível em: <https://www.flaticon. com>. Acesso em 31 out. 2019.

FREEPIK, Graphic resources for everyone, 2018. Disponível em: <https://www freepik. com>. Acesso em 31 out. 2019.

GOMBRICH, E. H. Meditações Sobre um Cavalinho de Pau e Outros - Ensaios sobre a Teoria da Arte. EdUSP - Editora da Universidade de São Paulo, São Paulo. Edição 1, 1999.

GOOGLE PLAY STORE, Plataforma Online. Disponível em: <https://play.google.com>. Acesso em 31 out. 2019.

HELLER, E. Psicologia das cores - Como as cores afetam a emoção e a razão Capa Comum. Editora Gustavo Gili; Edição 1, 2012. ISBN-13: 978-8565985079.

JOHNSON. S. Cultura da Interface - Como o Computador Transforma Nossa Maneira de Criar e Comunicar. Editora Digital Source. Rio de Janeiro. Tradução; Maria Luiza X. de A. Borges. 1997. ISBN 85-7110-589-8. Disponível em: <http://www.niett.unirio.br/public/upload/ ff79006eb77a377f5a7500dc5e672255.pdf>. Acesso em 29 nov. 2019.

NOVAK, J. Desenvolvimento de Games. Editora: Cengage CTP; Edição: 1, 2010. ISBN-10: 8522106320. ISBN-13: 978-8522106325

RICCI-BITTI, P.; Zani, B. A comunicação como processo social. Lisboa: Editorial Estampa. 1997.

SANTANDER. Prêmio Santander. 2014. Disponível em: <https://sustentabilidade.santander.com.br/pt/>. Acesso em 29 nov. 2018.

SARRISO, A. Jogo com "ratinho esperto" ajuda na alfabetização de crianças autistas. Matéria de Osvaldo Júnior, 2018 Disponível em: <https://www.campograndenews.com.br/ tecnologia/jogo-com-ratinho-esperto-ajuda-na-alfabetizacao-de-criancas-autistas>. Acesso em: 31 out. 2019.

SCHÜTTE, Simon. Designing Feelings into Products: Integrating Kansei Engineering Methodology in Product Development. 2002. 115f. Tese (Doutorado em Ciência e Tecnologia) - Department of Management and Engineering, Machine Design, Linköping University, Linköping, 2002. Disponível em: <http://liu.divaportal.org/smash/record.jsf?pid=diva2:19998>. Acesso em: 19 out. 2019. 